Article

\title{
The Influence of Epitaxial Crystallization on the Mechanical Properties of Polyamide 66/Reduced Graphene Oxide Nanocomposite Injection Bar
}

\author{
Enyi Chi ${ }^{1}$ (D), Minfang An ${ }^{1}$, Guibin Yao ${ }^{1}$, Feng Tian ${ }^{2,3}$ and Zongbao Wang ${ }^{1, *}$ \\ 1 Ningbo Key Laboratory of Specialty Polymers, Faculty of Materials Science and Chemical Engineering, \\ Ningbo University, Ningbo 315211, China; chienyi2017@outlook.com (E.C.); anminfang@126.com (M.A.); \\ yaoguibin123@163.com (G.Y.) \\ 2 Shanghai Institute of Applied Physics, Chinese Academy of Sciences, Shanghai 201204, China; \\ tianfeng@sinap.ac.cn \\ 3 State Key Laboratory of Polymer Materials Engineering, Sichuan University, Chengdu 610065, China \\ * Correspondence: wangzongbao@nbu.edu.cn; Tel.: +86-0574-8760-0734
}

Academic Editor: Qing Peng

Received: 11 November 2017; Accepted: 18 December 2017; Published: 20 December 2017

\begin{abstract}
Polyamide 66 (PA66) was chosen as the representative of hydrophilic polymers, to investigate the influence of epitaxial crystals in semi-crystalline polymers/reduced graphene oxide nanocomposite injection-molding bars. A differential scanning calorimeter was used, and the two-dimensional wide-angle $X$-ray diffraction technique, as well as the two-dimensional small angle X-ray scattering technique, were used to research the crystallization behavior in PA66/RGO nanocomposites. The results indicated that RGO was an effective nucleation agent for PA66. The presence of RGO could enhance the orientation degree of the PA66 crystals and did not influence the crystal structure of the PA66. The non-epitaxial crystals and the epitaxial crystals existed in PA66/RGO nanocomposites. The size of epitaxial crystals was much greater than that of the non-epitaxial crystals. Tensile test results showed that the presence of fewer epitaxial crystals can improve the mechanical properties of a polymer.
\end{abstract}

Keywords: polyamide 66; reduced graphene oxide; nanocomposite; epitaxial crystal

\section{Introduction}

Polymer nanocomposites, especially polymer-inorganic nanocomposites, have attracted considerable attention on account of their excellent mechanical properties and functions in recent years [1-4]. The ability of interfacial interactions between inorganic nanomaterials and polymers is the most important factor for the high-performance polymer-inorganic nanocomposite [5-7]. The studies on the interfacial interactions of polymers and filler focus on the following four strategies: (1) surface modification of the nanomaterial [8-11]; (2) modification of the polymer [12]; (3) preparing polymer composites via an in-situ polymerization method [13-15]; and (4) adding a compatibilizer [16,17]. The physical method can enhance interfacial interactions and avoid the destruction of the structure and properties of inorganic nanomaterial. Fu et al. have proved that interfacial crystallization could effectively enhance interfacial interactions [18]. The epitaxial crystallization is a kind of interfacial crystallization. Therefore, the epitaxial crystallization of semi-crystalline polymer on the surface of a layered inorganic nanomaterial can effectively enhance interfacial interactions. Epitaxy is defined as the growth of one phase on the surface of another phase in one or more strictly defined crystallographic orientations. This orientation is explained by a two- or one-dimensional structural analogy in the plane of contact between the two crystal types [19]. Pashley indicates that $10-15 \%$ disregistries of lattice matching are the upper limit of epitaxy [20]. 
The two-dimensional graphene is an atomically thin chip composed of $\mathrm{sp}^{2}$ carbon atoms arranged in a honeycomb structure [21,22]. Graphene is one of the strongest materials found to date [23] and has great potential for improving the mechanical properties of polymers [24-29]. Reduced graphene oxides (RGO) are typical graphene materials with slight topological defects in their periodic structures [22]. Compared to graphene, RGO possesses better dispersibility in polymers since it has only a few oxygen atoms. Hence, research on epitaxial crystallization in polymer/RGO nanocomposites has attracted considerable attention. In our previous papers, the influence of the epitaxial crystallization was studied in high crystallization polycaprolactone (PCL)/RGO nanocomposites [30,31]. The disregistry between the c-axis of PCL and the crystallographic parameter of $<2100>$ RGO spacing is $0.2 \%$ [31,32]. The crystallization of the PCL matrix epitaxially grows on the interface of laminated RGO. The orientation of crystals in PCL/RGO nanocomposites obviously enhances, and its mechanical property significantly improves. Analogously, another high crystallization polyethylene (PE) can epitaxially grow on the interface of laminated RGO and the mechanical properties of PE/RGO nanocomposite were improved [33,34]. However, the influence of epitaxial crystallization in a semi-crystalline polymer with H-bond and RGO nanocomposites is rarely mentioned in industrial production modeling.

Polyamide 66 (PA66) is widely used in engineering plastics due to its excellent properties. PA66 and its nanocomposites are continuously studied [35-37]. Semi-crystalline polymer PA66 possesses a lot of hydrophilic groups. The key factor for the crystal structures formed is the ability of the $\mathrm{NH}$ group to form H-Bonds with the $\mathrm{CO}$ group in PA66. In the injection molding process, the $\alpha$ structure is the main physical structure of the PA66 crystal. In the $\alpha$ structure, the PA66 chains are in the fully extended planar zigzag conformation. The crystal structure of PA66 is triclinic. The lattice constants of PA66 crystal are $a=0.49 \mathrm{~nm}, \mathrm{~b}=0.54 \mathrm{~nm}, \mathrm{c}=1.72$ $\mathrm{nm}$ [38]. The crystallographic parameter of the <2100> RGO spacing is $0.246 \mathrm{~nm}$ [39]. Hence, the disregistry between the c-axis of the PA66 crystal and the crystallographic parameter of $<2100>$ RGO spacing is $0.1 \%$, which is lower than PCL/RGO nanocomposites. The crystal of PA66 can, in theory, epitaxially grow on the surface of laminated RGO. Because of the existence of H-bonds, RGO more easily absorbs the chains of hydrophilic PA66. Therefore, PA66 was chosen as the representative of semi-crystalline polymers with $\mathrm{H}$-bonds to investigate the effect of epitaxial crystals in semi-crystalline polymer/RGO nanocomposites.

In this study, neat PA66 and 0.1 wt\% RGO (PA66/RGO0.1), $0.5 \mathrm{wt} \%$ RGO (PA66/RGO0.5) and $1.0 \mathrm{wt} \%$ RGO (PA66/RGO1.0) nanocomposites were obtained by injection molding. The mechanical properties of PA66/RGO nanocomposites were compared to different samples and the wide-angle $\mathrm{X}$-ray diffraction, as well as the small-angle $\mathrm{X}$-ray scattering, and differential scanning calorimetry measurements were used to study the structure of PA66/RGO nanocomposites. The impact of epitaxial crystallization on the crystal structure and orientation, as well as the relation between the epitaxial crystallization and the mechanical properties of PA66/RGO nanocomposites were discussed.

\section{Results and Discussion}

DSC curves of neat PA66 and PA66/RGO nanocomposites are shown in Figure 1. The melting temperature $\left(T_{m}\right)$ (Figure 1a) is about $263.5^{\circ} \mathrm{C}$ in all four samples, but the peaks of the samples widen with the addition of RGO, suggesting that different crystals exist in PA66/RGO nanocomposites. The crystallization temperature $\left(T_{c}\right)$ of neat PA66, PA66/RGO0.1, PA66/RGO0.5 and PA66/RGO1.0 (Figure $1 \mathrm{~b}$ ) are $232.8^{\circ} \mathrm{C}, 238.5^{\circ} \mathrm{C}, 243.6^{\circ} \mathrm{C}$ and $244.5^{\circ} \mathrm{C}$, respectively. With the increase of RGO, $T_{c}$ of the samples gradually increases. Based on the measured heat of fusion of neat PA66 (34.5 J/g), PA66/RGO0.1 (33.1 J/g), PA66/RGO0.5 (31.2 J/g) and PA66/RGO1.0 (30.7 J/g) from Figure 1a and $188.4 \mathrm{~J} / \mathrm{g}$ heat of fusion of $100 \%$ crystalline PA66, the crystallinity of test samples are $18.3 \%, 17.5 \%, 16.5 \%$ and $16.2 \%$, respectively $[40,41]$. Even if RGO is added, the crystallinity of PA66 and its nanocomposites is not enhanced. The results suggest that RGO provides heterogeneous nucleation sites for PA66 in the nanocomposites and that different crystals exist in PA66/RGO nanocomposites [29]. 

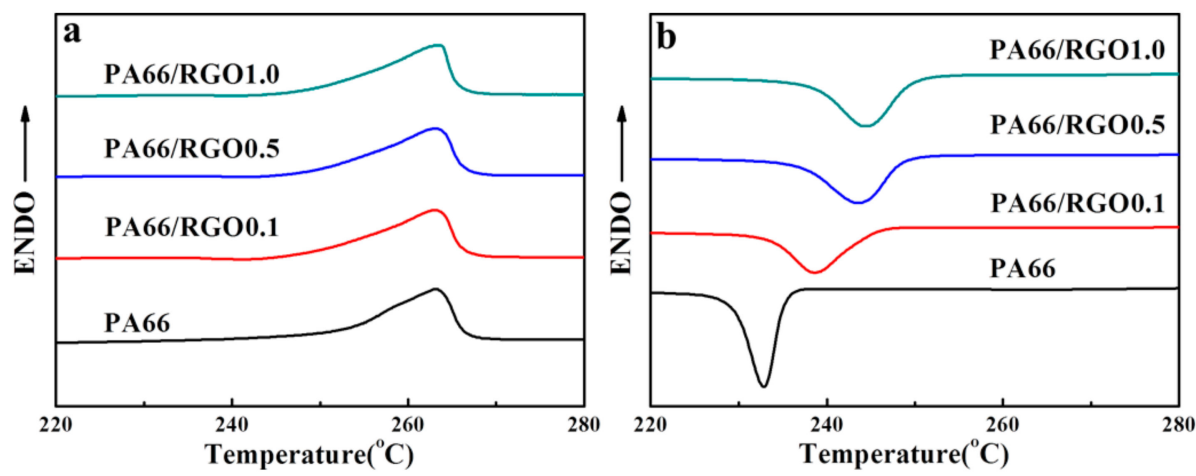

Figure 1. (a) The heating curves and (b) the cooling curves of neat PA66 and PA66/RGO0.1, PA66/RGO0.5 and PA66/RGO1.0 nanocomposites.

Figure 2 shows the 2D-WAXD patterns obtained at the intermediate zones of injection-molded bars of the test samples. From the innermost to the outermost, the diffraction circles are designated to the (100) and (010) + (110) crystal planes of PA66 triclinic crystals, respectively [38]. WAXD curves of neat PA66 and PA66/RGO nanocomposites collected from 2D-WAXD patterns (Figure 2) are shown in Figure 3. The $2 \theta$ corresponding to (100) and (010) $+(110)$ crystal planes are $16.3^{\circ}$ and $19.0^{\circ}$ in WAXD curves. Because the $2 \theta$ of the test samples are same, RGO does not affect the crystal form of PA66. When recollected, the DSC result showed that the peaks widen with the addition of RGO, which indicates that crystals with the same crystal form but different thicknesses exist in PA66/RGO nanocomposites. The crystalline degree calculated from WAXD patterns (Figure 2) is shown in Figure 4 for neat PA66 and its nanocomposites. The crystalline degree of neat PA66 and PA66/RGO0.1 is 17.6\%, but the value reduces to $17.3 \%$ and $17.0 \%$ as the RGO contents change to 0.5 , and $1.0 \mathrm{wt} \%$. Therefore, on the basis of the DSC and WAXD results, the crystalline degree of PA66 slightly reduces with the increase of RGO in the PA66/RGO nanocomposites. The result of the crystalline degree is consistent with the result of the PE/RGO nanocomposites [42]. It may be due to the fact that RGO hinders the motion of polymer chains.
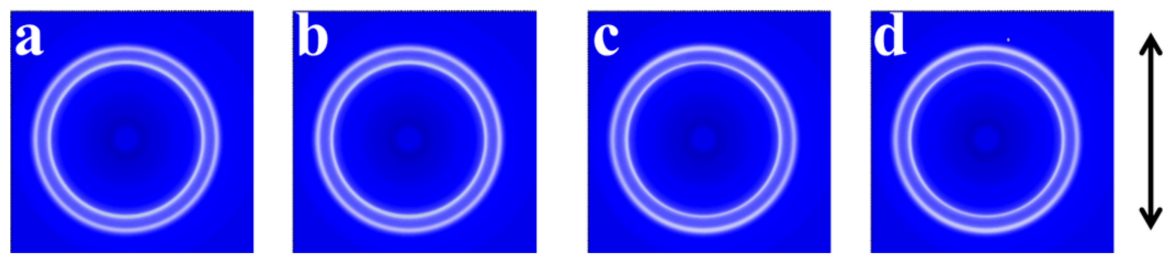

Figure 2. The 2D-WAXD patterns of (a) PA66, (b) PA66/RGO0.1, (c) PA66/RGO0.5 and (d) PA66/RGO1.0; The direction of the double-arrow was parallel to the flow direction.

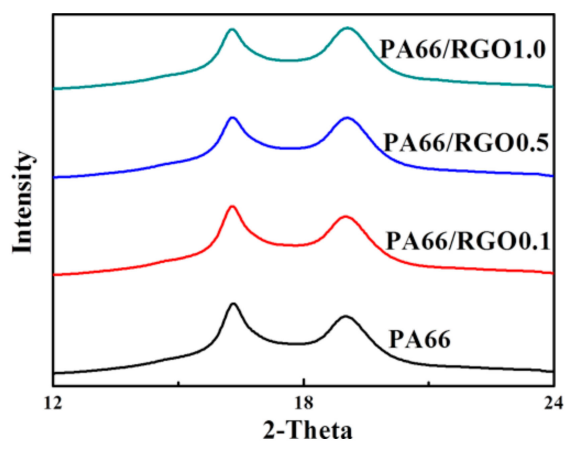

Figure 3. The 2D-WAXD curves of neat PA66 and PA66/RGO0.1, PA66/RGO0.5, and PA66/ RGO1.0 nanocomposites. 


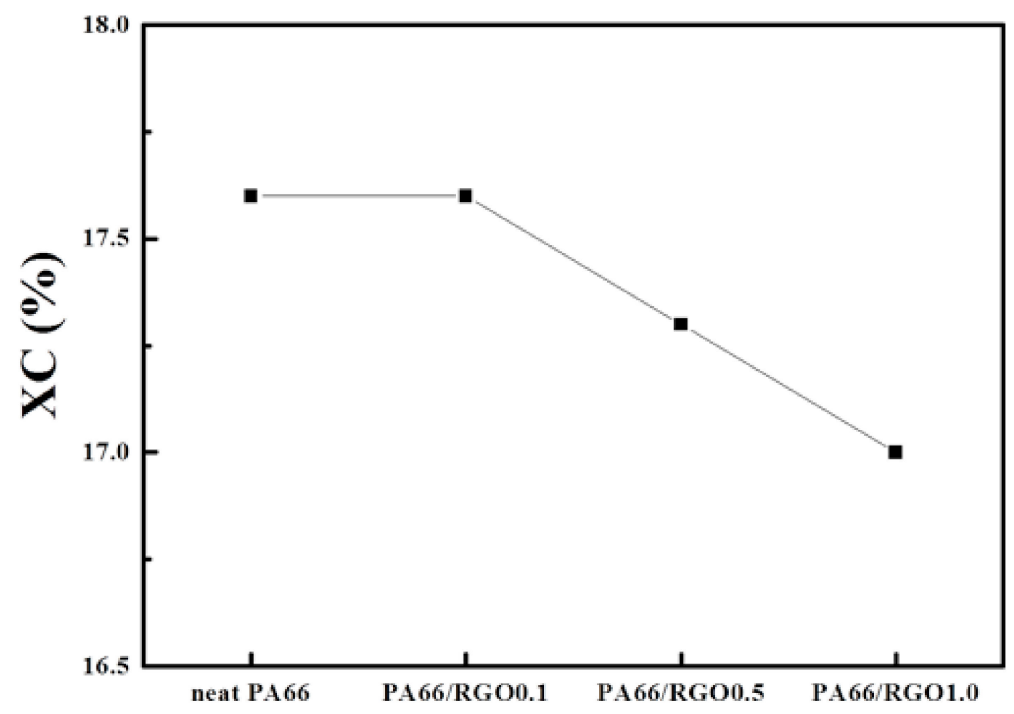

Figure 4. The crystalline degree of neat PA66 and PA66/RGO0.1, PA66/RGO0.5, and PA66/ RGO1.0 nanocomposites.

Furthermore, the WAXD was used to study the effect of RGO nanofillers. In the non-isothermal crystallization process, fewer PA66 crystals exist in the test samples. The change of the orientation of the neat PA66 and PA66/RGO nanocomposites is hardly observed in 2D-WAXD patterns. The 3D-WAXD patterns were obtained from Figure 2, as shown in Figure 5. With the increase of RGO, the two diffraction rings have no obvious change in the 2D-WAXD patterns (Figure 2) but the intensity and orientation of the two diffraction rings of the crystal planes changed in the 3D-WAXD patterns (Figure 5). In the 3D-WAXD pattern, the orientation of the (100) crystal plane is perpendicular to the flow direction, intensity and orientation of the (010) enhanced crystal plane when RGO is added into the PA66. In Figure 5a, the weak crystal orientation of the neat PA66 bar is parallel to the injection flow direction. When the $0.1 \mathrm{wt} \%$ RGO is added, because only a small number of epitaxial crystals exist, the orientation of PA66/RGO0.1 nanocomposite is akin to that of the neat PA66 (Figure 5b). However, the degree of orientations of PA66/RGO0.5 and PA66/RGO1.0 nanocomposites increases (Figure $5 c, d$ ). In the injection process, the chains of the PA66 and RGO are subjected to an intensive shear flow and are parallel to the flow direction. The relaxation of PA66 chains occurs in non-isothermal crystallization, but RGO can restrict the mobility of the PA66 matrix chains by H-bond interaction and epitaxial crystallization. Therefore, the orientation of PA66/RGO nanocomposites is enhanced.

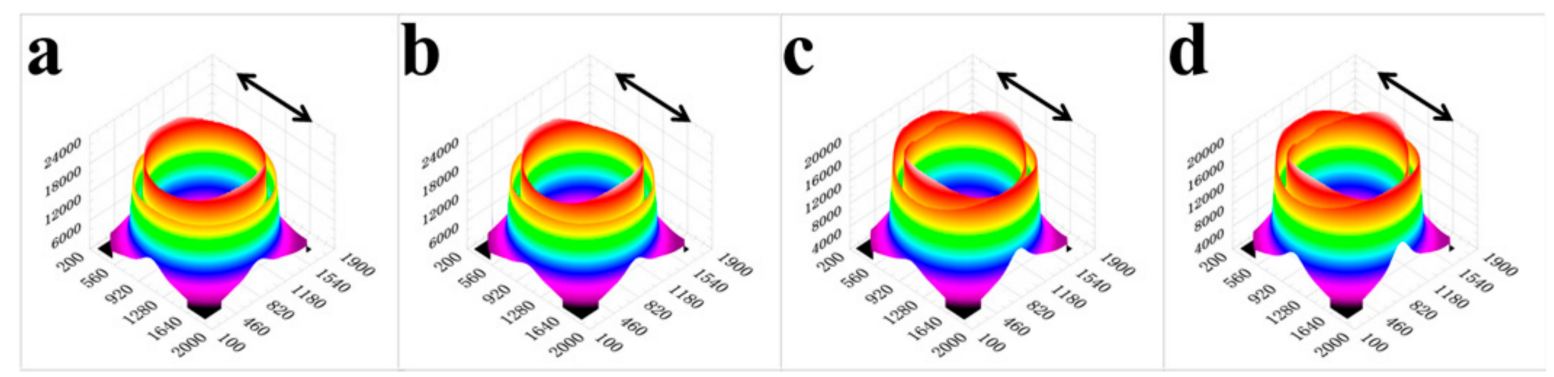

Figure 5. The 3D-WAXD patterns of (a) PA66, (b) PA66/RGO0.1, (c) PA66/RGO0.5 and (d) PA66/ RGO1.0. The direction of the double-arrow was parallel to the flow direction.

The SAXS measurement was used to investigate the structure of PA66/RGO nanocomposites. Figure 6 shows 2D-SAXS patterns of neat PA66 and its nanocomposites. In 2D-SAXS patterns, the scattered signals consist of the center signal and the outer signal. The outer signal of 2D-SAXS 
patterns is waning. Because of the low crystallinity of the PA66 matrix, the scattered signal of test samples is weak. By the program FIT2D, 1D-SAXS curves are obtained from 2D-SAXS patterns. The Lorenz-corrected SAXS curves (Figure 7) were collected from the 2D-SAXS patterns in Figure 6. As shown in Figure 7, the Lorenz-corrected curves of the test samples have multiple scattering peaks, except for the neat PA66. Moreover, $\mathrm{q}_{1}$ and $\mathrm{q}_{2}$ represent the first scattering peak position and the second scattering peak position in the scattering curves, respectively. The 1D-SAXS pattern of neat PA66 does not have a $q_{1}$ peak, but the intension of a $q_{1}$ peak of the PA66/RGO nanocomposites gradually increase with the addition of RGO. The addition of RGO brings the PA66 nanocomposites to the new period structure. The sample-to-detector distance of $2320 \mathrm{~mm}$ was used to capture the second peak position (Figure 8). With an increase of RGO, the strength of the second peak declines gradually. The long period of the PA66 matrix was calculated using the Bragg equation, $L=2 \pi / q$, where $L$ is the long period, and q represents the peak position in the scattering curves. $\mathrm{L}_{1}$ and $\mathrm{L}_{2}$ were calculated to be $62.83 \mathrm{~nm}$ and $7.85 \mathrm{~nm}$, respectively. The Lorenz-corrected SAXS curves of the neat PA66 are different from that of the other nanocomposites. The addition of RGO is the cause of the emergence of $\mathrm{q}_{1}$. With the addition of RGO, epitaxial growth of PA66 chains occurs on the surface of RGO. Therefore, $\mathrm{L}_{1}$ and $\mathrm{L}_{2}$ are connected with epitaxial crystals and non-epitaxial crystals, respectively. Therefore, the addition of RGO can bring the PA66 nanocomposites to the new period structure, enabling the existence of epitaxial crystals.
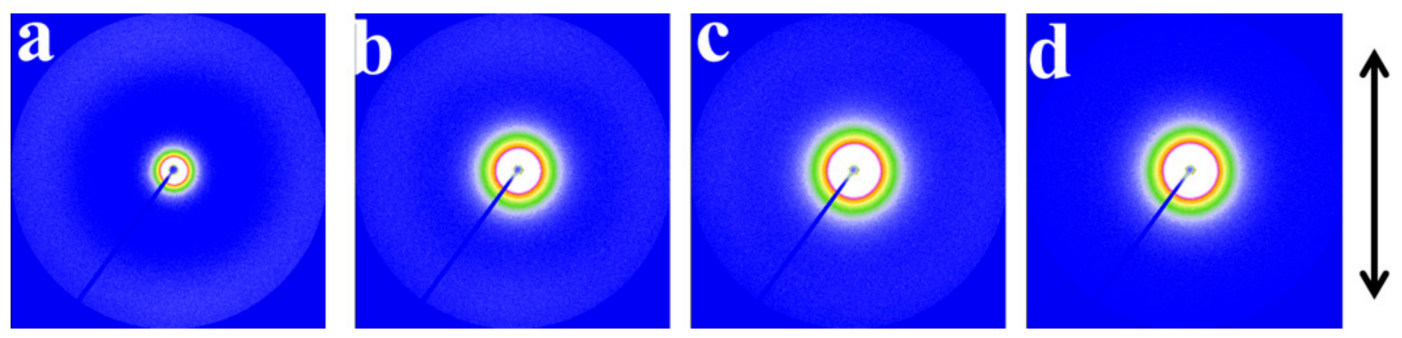

Figure 6. The 2D-SAXS patterns of (a) PA66, (b) PA66/RGO0.1, (c) PA66/RGO0.5 and (d) PA66/RGO1.0. The sample-to-detector distance was $5210 \mathrm{~mm}$. The direction of the double-arrow was parallel to the flow direction.

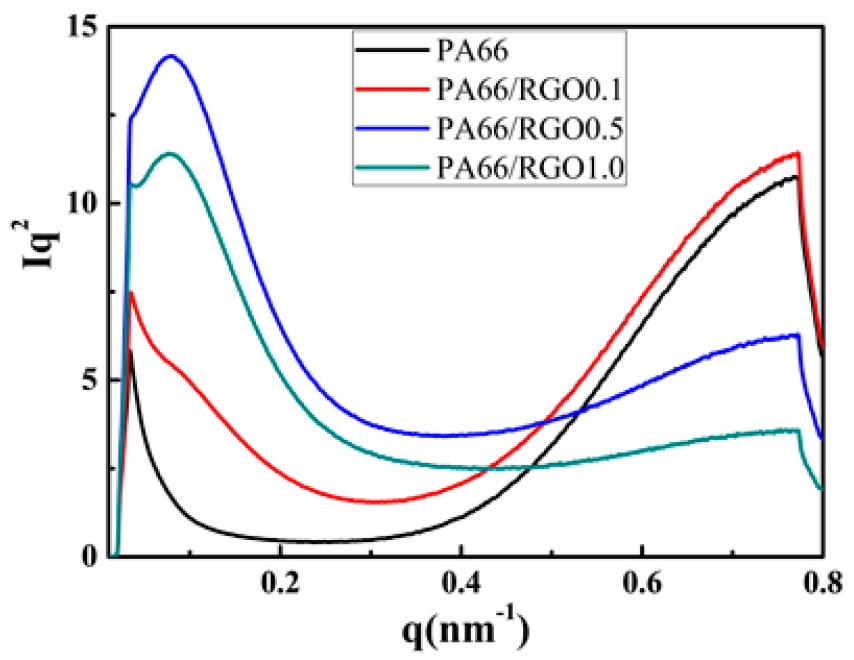

Figure 7. The Lorentz-corrected SAXS curves of neat PA66 and PA66/RGO0.1, PA66/RGO0.5 and PA66/RGO1.0 nanocomposites. The sample-to-detector distance was $5210 \mathrm{~mm}$. 


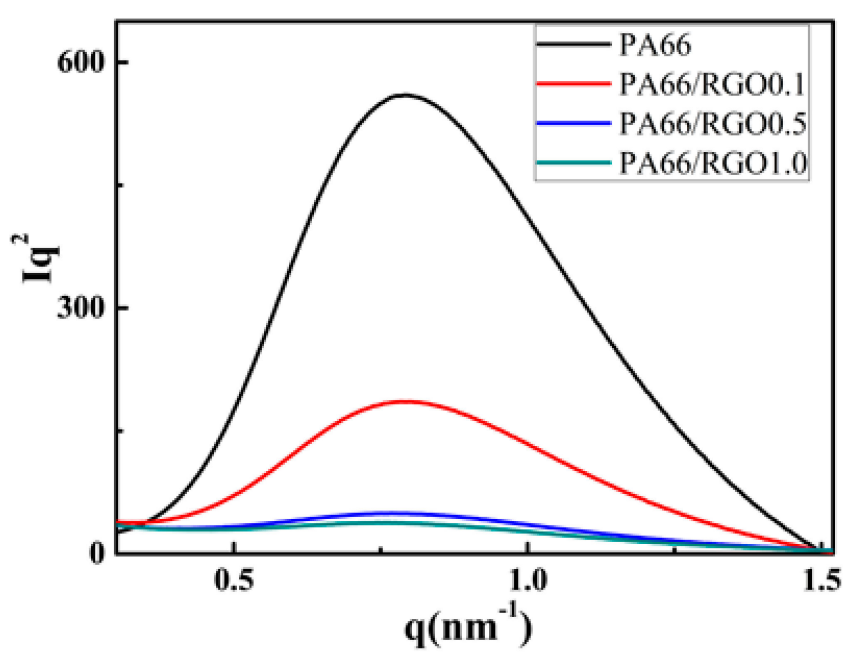

Figure 8. The Lorentz-corrected SAXS curves of neat PA66 and PA66/RGO0.1, PA66/RGO0.5 and PA66/RGO1.0 nanocomposites. The sample-to-detector distance was $2320 \mathrm{~mm}$.

The platy RGO nano-filler can effectively enhance the orientation of nanocomposites [43]. Further study of crystal orientation was carried out using the 2D-SAXS experiment. The azimuthally integrated profiles of Figures 9 and 10 were collected from the outer and center signals of 2D-SAXS patterns, respectively. In the azimuthally integrated profiles of outward scattering signals (Figure 9), the signal intensity weakens. As shown in Figure 10, the 2D-SAXS signal of PA66/RGO nanocomposites was distributed in the meridian direction. It is observed that the orientation degree of the PA66 chain is enhanced in the parallel direction of the flow with the increase of platy RGO. It is consistent with the results of WAXD.

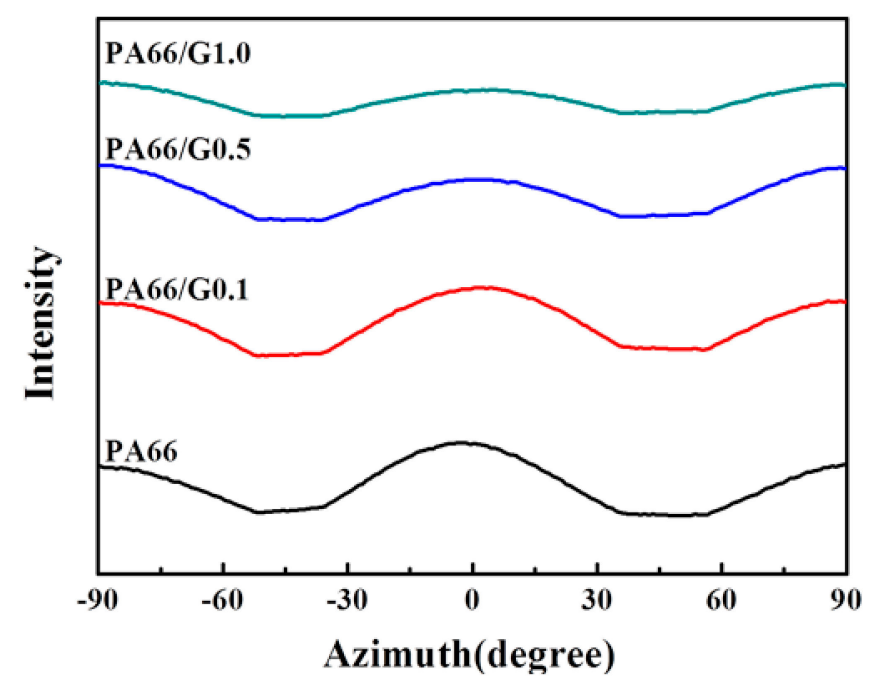

Figure 9. Azimuthally integrated profiles of the outer scattering signal of neat PA66 and PA66/RGO0.1, PA66/RGO0.5 and PA66/RGO1.0 nanocomposites. 


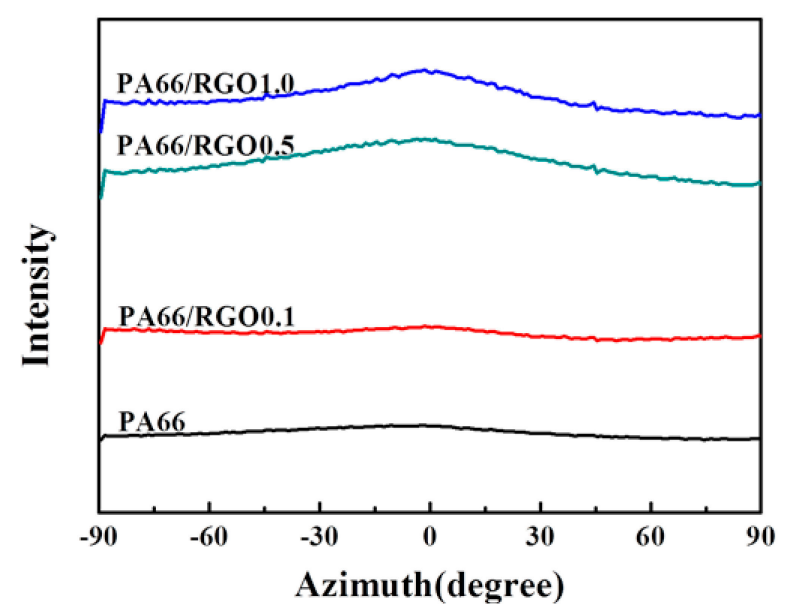

Figure 10. Azimuthally integrated profiles of the center scattering signal of neat PA66 and PA66/RGO0.1, PA66/RGO0.5 and PA66/RGO1.0 nanocomposites.

On account of the existence of epitaxial crystals, the mechanical properties of nanocomposites could be affected. The stress-strain curves of the neat PA66 and its nanocomposites are shown in Figure 11. The change of strain is outstanding. The tensile strength of the neat PA66 and $0.1 \mathrm{wt} \%$ PA66/RGO nanocomposite is $74.3 \pm 2.8$ and $74.7 \pm 1.7 \mathrm{MPa}$, respectively. The tensile strength of $0.1 \mathrm{wt} \%$ PA66/RGO nanocomposites is not obviously improved. However, compared to the neat PA66, the tensile strength of samples increased from $74.3 \pm 2.8$ to $76.3 \pm 1.7$ and $77.3 \pm 2.4 \mathrm{MPa}$ for $0.5 \mathrm{wt} \%$ and $1.0 \mathrm{wt} \%$ PA66/RGO for nanocomposites. Petermann et al. reported that strong adherence of epitaxial interfaces in semi-crystalline polymers was responsible for the improvement in mechanical properties [5-7]. The effective interface interactions between the polymer and nanofiller could enhance the tensile strength of the polymer matrix [44]. For example, the tensile strength of PCL/RGO nanocomposites and PE/RGO nanocomposites can increase by $12 \%$ and $10 \%$, respectively [30,34]. As mentioned above, PA66 crystals in PA66/RGO nanocomposites can epitaxially grow on the face of platy RGO. Epitaxy effectively enhances the interfacial interactions of the PA66 matrix and RGO nanofiller. In spite of the existence of a small quantity of interfacial crystallization, the tensile strength of PA66/RGO nanocomposites can be enhanced. In this study, this improvement in mechanical properties can be attributed to three reasons: (i) RGO has excellent mechanical strength; (ii) RGO could enhance the orientation of PA66/RGO nanocomposites; (iii) Epitaxial crystallization could effectively enhance interfacial interaction.

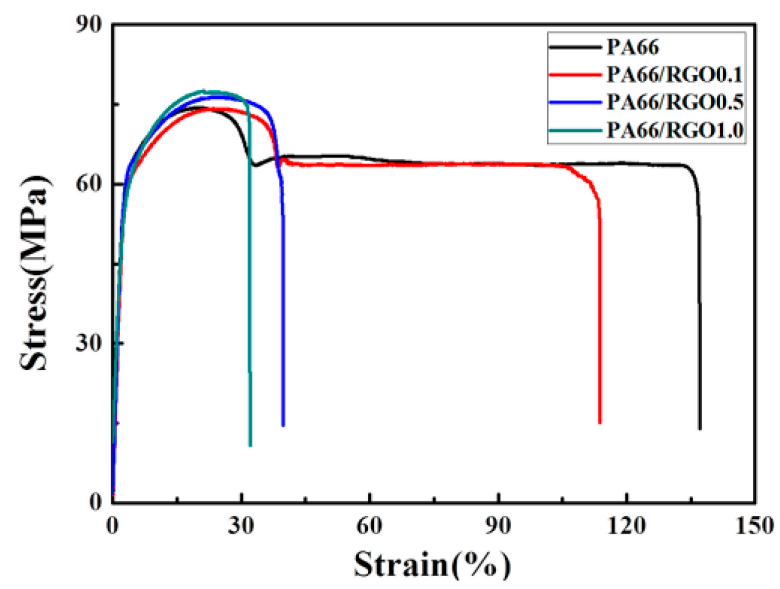

Figure 11. Stress-strain curves of neat PA66 and PA66/RGO0.1 (0.1 wt \% RGO), PA66/RGO0.5 (0.5 wt\% RGO) and PA66/RGO1.0 (1.0 wt\% RGO) nanocomposites. 
Because all the test bars are injection-molded samples, the neat PA66 and its nanocomposites undergo the non-isothermal crystallization process. Furthermore, the disregistry between the c-axis of the PA66 crystal and the crystallographic parameter of $<2100>$ RGO spacing is $0.1 \%$. PA66 crystals can epitaxially grow on the face of platy RGO. However, the crystalline degree of the neat PA66 and PA66/RGO nanocomposites is less than $17.6 \%$, and the crystalline structure has not changed. Consequently, there are only a few crystals in the test bars. In the injection-molding process, the lamellae of PA66 crystals cannot pile up to form a lamellar layer structure [45]. A large amount of matter in the amorphous exists between the crystals. The crystals are scattered in the amorphous phase of the PA66, and the distance between adjacent crystals is very dissimilar. Therefore, $\mathrm{L}_{1}$ and $\mathrm{L}_{2}$ represent the period structure in the neat PA66 and its nanocomposites. The ability to form H-bonds between the $\mathrm{NH}$ group and the $\mathrm{CO}$ group is the determining factor for the crystal structures in PA66 [46]. Bunn and Garner reported that the chains in the $\alpha$ structure of PA66 were in the fully extended planar zig-zag conformation and parallel to the c-axle direction [38]. For the presence of a maximum amount of $\mathrm{H}$-bonds, the size of the epitaxial crystal is far greater than that of the non-epitaxial crystal. $\mathrm{L}_{2}$ is about $7.85 \mathrm{~nm}$ for PA66 and PA66/RGO nanocomposites and the SAXS curve of neat PA66 has only one peak; $L_{2}$ represents the structure of the non-epitaxial crystal. As RGO is added, the other long period $\left(\mathrm{L}_{1}=62.83 \mathrm{~nm}\right)$ arises. Evidently, $\mathrm{L}_{1}$ is the period structure of epitaxial crystals. Therefore, the crystals of PA66/RGO nanocomposites include the non-epitaxial and epitaxial crystals, and the size of the epitaxial crystal is much greater than the non-epitaxial crystals. These results indicate that, with the addition of platy RGO, the crystal structure and the crystalline degree of the PA66 matrix are unchanged, but a part of the non-epitaxial crystals is replaced with the epitaxial crystals.

In the injection-molding samples, the chains of PA66 and platy RGO are subjected to intensive shear flow in the injection molding process. As the amount of RGO is increased, the epitaxial crystals gradually become the main portion of PA66 crystal. In the non-isothermal crystallization process, not only is the crystal of the PA66 matrix epitaxial on the surface of platy RGO, but also the (100) crystal plane is parallel to the platy RGO [32]. The orientation of platy RGO is parallel to the injection flow direction in the injection-molding process. Under the influence of the shear field, the chains of the PA66 matrix are parallel to the injection flow direction and the platy RGO. Furthermore, because of the presence of RGO, the mobility of PA66 matrix chains is restricted. During the cooling process, the orientation of the PA66 chains in the epitaxial crystals is kept. Therefore, the degree of their orientations increases. These results indicate that the degree of orientation depends on the proportion of epitaxial crystals in the polymer nanocomposite. The crystal orientation of the PA66 matrix is enhanced with the increase of RGO. In PA66/RGO nanocomposites, a 2D layered RGO could absorb the PA66 chain and provide the base for the epitaxial crystal of the PA66 matrix. In high-crystallinity PCL/RGO and PE/RGO nanocomposites, the existence of numerous epitaxial crystals can greatly improve its mechanical properties. In the hydrophilic PA66 matrix, there are fewer epitaxial crystals. The tensile strength of hydrophilic PA66/RGO nanocomposites is increased by $4 \%$. This indicates that the quantity of the epitaxial crystals influences the improvement of mechanical properties.

\section{Materials and Methods}

\subsection{Materials}

The PA66 (101L NC010) $\left(\rho: 1.14 \mathrm{~g} / \mathrm{cm}^{3}\right)\left(\right.$ MFI: $\left.2.0\left(230^{\circ} \mathrm{C} / 3.8 \mathrm{~kg}\right)\right)$ used in this work was purchased from DuPont Ltd. (Wilmington, DE, USA). Natural flake graphite was supplied by Qingdao Jiuyi Graphite Co., Ltd. (Shandong, China) with a mean particle size of $50 \mu \mathrm{m}$.

\subsection{Sample Preparation}

The GO was exfoliated by ultra-sonication from graphite oxide which was produced by modified Hummers' method [47]. The RGO was prepared by thermal exfoliation and the reduction of GO [31]. 
The PA66 granules used were dried in a vacuum oven at $110^{\circ} \mathrm{C}$ for at least $12 \mathrm{~h}$ prior to blending with the RGO. The temperature of the twin-screw extruder (HAAKE MiniLab II, Thermo Scientific, Waltham, MA, USA) (L/D: 22) was maintained at $275^{\circ} \mathrm{C}$. The screw speed was maintained $60 \mathrm{rpm}$. The obtained nanocomposites were injection-molded to obtain test bars (50 $\mathrm{mm} \times 4 \mathrm{~mm} \times 2 \mathrm{~mm}$ ) in the Thermal scientific HAAKE MiniLab II. The injection-molding mold temperature and injection pressure were $150{ }^{\circ} \mathrm{C}$ for $10 \mathrm{~min}$ and 700 bar.

\subsection{Analytical Methods}

The differential scanning calorimetry (DSC) measurements were performed with Thermal Analyst Q1000 DSC (TA Instruments, New Castle, DE, USA) under a nitrogen atmosphere. All samples were heated to $280{ }^{\circ} \mathrm{C}$ at a heating rate of $10^{\circ} \mathrm{C} / \mathrm{min}$, and equilibrated at $280^{\circ} \mathrm{C}$ for $3 \mathrm{~min}$ to remove all thermal history. Subsequently, the samples were cooled to $25^{\circ} \mathrm{C}$ at a cooling rate of $10^{\circ} \mathrm{C} / \mathrm{min}$.

Two-dimensional wide-angle X-ray diffraction (2D-WAXD) and two-dimensional small angle X-ray scattering (2D-SAXS) experiments were carried out on the BL16B1 beam-line in the Shanghai Synchrotron Radiation Facility (SSRF). The monochromatic X-ray wavelength was $1.239 \AA$, and the $2 \mathrm{D}$ patterns were recorded in transmission mode at room temperature. The sample-to-detector of the 2D-WAXD experiment was $172.4 \mathrm{~mm}$. The sample-to-detector distances of the 2D-SAXS experiments were $5210 \mathrm{~mm}$ and $2320 \mathrm{~mm}$. The data of the WAXD and the SAXS experiments were analyzed by the program FIT2D (A. Ham-mersley, European synchrotron Radiation Facility, Grenoble, France). Using the program Xpolar, the crystallinity was acquired from a 2D-WAXD test.

A tensile test was performed on Instron 5567 (Instron Co., Norwood, MA, USA) at a tensile rate of $10 \mathrm{~mm} / \mathrm{min}$. Five standard bars for each sample were measured and the average values were calculated.

\section{Conclusions}

The epitaxial crystallization of hydrophilic semi-crystallinity polymer/RGO nanocomposites was investigated in detail. The following conclusions can be drawn from the current study.

1. Platy RGO is a nucleation agent to assist the crystallization of PA66 but does not influence the crystal structure, and can enhance the orientation degree of PA66 chains in the flow direction.

2. The crystal of PA66/RGO nanocomposites includes the non-epitaxial crystal and the epitaxial crystal; the size of the epitaxial crystal is much greater than that of the non-epitaxial crystal.

3. The orientation degree of PA66/RGO nanocomposites is determined by the proportion of epitaxial crystals present when platy RGO is added; the non-epitaxial crystal orientation of the PA66 matrix is unchanged.

4. The presence of fewer epitaxial crystals can improve the mechanical properties of a polymer. The tensile strength of hydrophilic PA66/RGO nanocomposites is increased by $4 \%$.

Acknowledgments: This work was supported by the National Science Foundation of China (U1532114, 51773101), and K. C. Wong Magna Fund in Ningbo University. Financially Supported by the Opening Project of State Key Laboratory of Polymer Materials Engineering (Sichuan University) (Grant No. sklpme2016-4-26). We thank Shanghai Synchrotron Radiation Facility (SSRF) for supporting the SAXS and WAXD test.

Author Contributions: Zongbao Wang and Enyi Chi conceived and designed the experiments; Enyi Chi performed the experiments; Enyi Chi analyzed the data; Minfang An, Guibin Yao and Feng Tian contributed reagents/materials/analysis tools; Enyi Chi wrote the paper.

Conflicts of Interest: The authors declare no conflict of interest. The founding sponsors had no role in the design of the study; in the collection, analyses, or interpretation of data; in the writing of the manuscript, and in the decision to publish the results.

\section{References}

1. Gray, D.H.; Hu, S.L.; Juang, E.; Gin, D.L. Highly ordered polymer-inorganic nanocomposites via monomer self-assembly: In situ condensation approach. Adv. Mater. 1997, 9, 731-736. [CrossRef] 
2. Rahmat, M.; Hubert, P. Carbon nanotube-polymer interactions in nanocomposites: A review. Compos. Sci. Technol. 2011, 72, 72-84. [CrossRef]

3. Takenaka, Y.; Miyaji, H.; Hoshino, A.; Tracz, A.; Jeszka, J.K.; Kucinska, I. Interface structure of epitaxial polyethylene crystal grown on HOPG and MoS2 substrates. Macromolecules 2004, 37, 9667-9669. [CrossRef]

4. Li, C.Y.; Li, L.; Cai, W.; Kodjie, S.L.; Tenneti, K.K. Nanohybrid shish-kebabs: Periodically functionalized carbon nanotubes. Adv. Mater. 2005, 17, 1198-1202. [CrossRef]

5. Petermann, J.; Broza, G.; Rieck, U.; Kawaguchi, A. Epitaxial interfaces in semi-crystalline polymers and their applications. J. Mater. Sci. 1987, 22, 1477-1481. [CrossRef]

6. Petermann, J.; Xu, Y. Mechanical properties of epitaxially crystallized 1,4-polybutadiene on uniaxially oriented isotactic polypropylene. Colloid Polym. Sci. 1991, 269, 455-459. [CrossRef]

7. Gross, B.; Peterman, J. Synergisms of mechanical properties in blends of semi-crystalline polymers. J. Mater. Sci. 1984, 19, 105-112. [CrossRef]

8. Ramanathan, T.; Abdala, A.A.; Stankovich, S.; Dikin, D.A.; Herrera-Alonso, M.; Piner, R.D.; Adamson, D.H.; Schniepp, H.C.; Chen, X.; Ruoff, R.S.; et al. Functionalized graphene sheets for polymer nanocomposites. Nat. Nanotechnol. 2008, 3, 327-331. [CrossRef] [PubMed]

9. Deng, Y.; Li, Y.J.; Dai, J.; Lang, M.D.; Huang, X.Y. An efficient way to functionalize graphene sheets with presynthesized polymer via ATNRC chemistry. J. Polym. Sci. Pol. Chem. 2011, 49, 1582-1590. [CrossRef]

10. Yang, B.-X.; Pramoda, K.P.; Xu, G.Q.; Goh, S.H. Mechanical reinforcement of polyethylene using polyethylene-grafted multiwalled carbon nanotubes. Adv. Funct. Mater. 2007, 17, 2062-2069. [CrossRef]

11. Cao, Y.W.; Lai, Z.L.; Feng, J.C.; Wu, P.Y. Graphene oxide sheets covalently functionalized with block copolymers via click chemistry as reinforcing fillers. J. Mater. Chem. 2011, 21, 9271-9278. [CrossRef]

12. Salavagione, H.J.; Martinez, G. Importance of covalent linkages in the preparation of effective reduced graphene oxide-poly(vinyl chloride) nanocomposites. Macromolecules 2011, 44, 2685-2692. [CrossRef]

13. Feng, L.; Zhou, Z.; Dufresne, A.; Huang, J.; Wei, M.; An, L. Structure and properties of new thermoforming bionanocomposites based on chitin whisker-graft-polycaprolactone. J. Appl. Polym. Sci. 2009, 112, 2830-2837. [CrossRef]

14. Hu, H.; Wang, X.; Wang, J.; Wan, L.; Liu, F.; Zheng, H.; Chen, R.; Xu, C. Preparation and properties of graphene nanosheets-polystyrene nanocomposites via in situ emulsion polymerization. Chem. Phys. Lett. 2010, 484, 247-253. [CrossRef]

15. Sun, T.; Garces, J.M. High-performance polypropylene-clay nanocomposites by in-situ polymerization with metallocene/clay catalysts. Adv. Mater. 2002, 14, 128. [CrossRef]

16. Kim, H.-S.; Lee, B.-H.; Choi, S.-W.; Kim, S.; Kim, H.-J. The effect of types of maleic anhydride-grafted polypropylene (MAPP) on the interfacial adhesion properties of bio-flour-filled polypropylene composites. Compos. Part A Appl. Sci. Manuf. 2007, 38, 1473-1482. [CrossRef]

17. Imase, T.; Ohira, A.; Okoshi, K.; Sano, N.; Kawauchi, S.; Watanabe, J.; Kunitake, M. AFM study of two-dimensional epitaxial arrays of $\operatorname{poly}(\gamma$-L-glutamates) with long n-alkyl side chains on graphite. Macromolecules 2003, 36, 1865-1869. [CrossRef]

18. Ning, N.; Fu, S.; Zhang, W.; Chen, F.; Wang, K.; Deng, H.; Zhang, Q.; Fu, Q. Realizing the enhancement of interfacial interaction in semicrystalline polymer/filler composites via interfacial crystallization. Prog. Polym. Sci. 2012, 37, 1425-1455. [CrossRef]

19. Cartier, L.; Okihara, T.; Ikada, Y.; Tsuji, H.; Puiggali, J.; Lotz, B. Epitaxial crystallization and crystalline polymorphism of polylactides. Polymer 2000, 41, 8909-8919. [CrossRef]

20. Pashley, D.W. The nucleation, growth, structure and epitaxy of thin surface films. Adv. Phys. 1965, 14, 327-416. [CrossRef]

21. Novoselov, K.S.; Geim, A.K.; Morozov, S.V.; Jiang, D.; Zhang, Y.; Dubonos, S.V.; Grigorieva, I.V.; Firsov, A.A. Electric field effect in atomically thin carbon films. Science 2004, 306, 666-669. [CrossRef] [PubMed]

22. Gomez-Navarro, C.; Meyer, J.C.; Sundaram, R.S.; Chuvilin, A.; Kurasch, S.; Burghard, M.; Kern, K.; Kaiser, U. Atomic structure of reduced graphene oxide. Nano Lett. 2010, 10, 1144-1148. [CrossRef] [PubMed]

23. Lee, C.; Wei, X.; Kysar, J.W.; Hone, J. Measurement of the elastic properties and intrinsic strength of monolayer graphene. Science 2008, 321, 385-388. [CrossRef] [PubMed]

24. Quaresimin, M.; Schulte, K.; Zappalorto, M.; Chandrasekaran, S. Toughening mechanisms in polymer nanocomposites: From experiments to modelling. Compos. Sci. Technol. 2016, 123, 187-204. [CrossRef] 
25. Kim, H.; Abdala, A.A.; Macosko, C.W. Graphene/polymer nanocomposites. Macromolecules 2010, 43, 6515-6530. [CrossRef]

26. Kuilla, T.; Bhadra, S.; Yao, D.; Kim, N.H.; Bose, S.; Lee, J.H. Recent advances in graphene based polymer composites. Prog. Polym. Sci. 2010, 35, 1350-1375. [CrossRef]

27. Verdejo, R.; Bernal, M.M.; Romasanta, L.J.; Lopezmanchado, M.A. Graphene filled polymer nanocomposites. J. Mater. Chem. 2011, 21, 3301-3310. [CrossRef]

28. Glover, A.J.; Cai, M.; Overdeep, K.R.; Kranbuehl, D.E.; Schniepp, H.C. In situ reduction of graphene oxide in polymers. Macromolecules 2011, 44, 9821-9829. [CrossRef]

29. Potts, J.R.; Dreyer, D.R.; Bielawski, C.W.; Ruoff, R.S. Graphene-based polymer nanocomposites. Polymer 2011, 52, 5-25. [CrossRef]

30. Wang, B.J.; Li, Y.G.; Weng, G.S.; Jiang, Z.Q.; Chen, P.; Wang, Z.B.; Gu, Q. Reduced graphene oxide enhances the crystallization and orientation of poly(epsilon-caprolactone). Compos. Sci. Technol. 2014, 96, 63-70. [CrossRef]

31. Wang, B.; Zhang, Y.; Zhang, J.; Li, H.; Chen, P.; Wang, Z.; Gu, Q. Noncovalent method for improving the interaction between reduced graphene oxide and poly(e-caprolactone). Ind. Eng. Chem. Res. 2013, 52, 15824-15828. [CrossRef]

32. Sano, M.; Sasaki, D.Y.; Kunitake, T. Polymerization-induced epitaxy: Scanning tunneling microscopy of a hydrogen-bonded sheet of polyamide on graphite. Science 1992, 258, 441-443. [CrossRef] [PubMed]

33. Cheng, S.; Chen, X.; Hsuan, Y.G.; Li, C.Y. Reduced graphene oxide-induced polyethylene crystallization in solution and nanocomposites. Macromolecules 2011, 45, 993-1000. [CrossRef]

34. Cao, Z.; Song, P.; Fang, Z.; Xu, Y.; Zhang, Y.; Guo, Z. Physical wrapping of reduced graphene oxide sheets by polyethylene wax and its modification on the mechanical properties of polyethylene. J. Appl. Polym. Sci. 2012, 126, 1546-1555. [CrossRef]

35. Araujo, E.M.; Araujo, K.D.; Paz, R.A.; Gouveia, T.R.; Barbosa, R.; Ito, E.N. Polyamide 66/brazilian clay nanocomposites. J. Nanomater. 2009, 2009, 136856. [CrossRef]

36. Song, L.; Hu, Y.; He, Q.; You, F. Study on crystallization, thermal and flame retardant properties of nylon 66/organoclay nanocomposites by in situ polymerization. J. Fire Sci. 2008, 26, 475-492. [CrossRef]

37. Qin, H.L.; Su, Q.S.; Zhang, S.M.; Zhao, B.; Yang, M.S. Thermal stability and flammability of polyamide 66/montmorillonite nanocomposltes. Polymer 2003, 44, 7533-7538. [CrossRef]

38. Bunn, C.W.; Garner, E.V. The crystal structures of two polyamides ('Nylons'). Proc. R. Soc. A Math. Phys. 1947, 189, 39-68. [CrossRef]

39. Meyer, J.C.; Geim, A.K.; Katsnelson, M.I.; Novoselov, K.S.; Booth, T.J.; Roth, S.T. The structure of suspended grapheme sheets. Nature 2007, 446, 60-63. [CrossRef] [PubMed]

40. Garcia, D.; Starkweather Jr, H.W. Hydrogen bonding in nylon 66 and model compounds. J. Polym. Sci. Pol. Phys. 1985, 23, 537-555. [CrossRef]

41. Lim, L.T.; Britt, I.J.; Tung, M.A. Sorption and transport of water vapor in nylon 6,6 film. J. Appl. Polym. Sci. 1999, 71, 197-206. [CrossRef]

42. Yao, G.; Duan, T.; An, M.; Xu, H.; Tian, F.; Wang, Z. The influence of epitaxial crystallization on the mechanical properties of a high density polyethylene/reduced graphene oxide nanocomposite injection bar. RSC Adv. 2017, 7, 21918-21925. [CrossRef]

43. Xu, J.Z.; Chen, C.; Wang, Y.; Tang, H.; Li, Z.M.; Hsiao, B.S. Graphene nanosheets and shear flow induced crystallization in isotactic polypropylene nanocomposites. Macromolecules 2011, 21, 53-63. [CrossRef]

44. Fukumaru, T.; Fujigaya, T.; Nakashima, N. Mechanical reinforcement of polybenzoxazole by carbon nanotubes through noncovalent functionalization. Macromolecules 2013, 46, 4034-4040. [CrossRef]

45. Yuan, M.; Turng, L.S. Microstructure and mechanical properties of microcellular injection molded polyamide-6 nanocomposites. Polymer 2005, 46, 7273-7292. [CrossRef] 
46. Trifan, D.S.; Terenzi, J.F. Extents of hydrogen bonding in polyamides and polyurethanes. J. Polym. Sci. 1958, 28, 443-445. [CrossRef]

47. Wang, Y.; Li, Z.; Hu, D.; Lin, C.T.; Li, J.; Lin, Y. Aptamer/graphene oxide nanocomplex for in situ molecular probing in living cells. J. Am. Chem. Soc. 2010, 132, 9274. [CrossRef] [PubMed] 